\title{
Prognostic implications of survivin and lung resistance protein in advanced non-small cell lung cancer treated with platinum-based chemotherapy
}

\author{
WENFENG HUANG*, YAN MAO*, YONGZI ZHAN, JIANFENG HUANG, XIANGPING WANG, \\ PENGHUI LUO, LI LI, DUNCHANG MO, QIONG LIU, HUIMIN XU and CHANGJIE HUANG
}

Tumor Department, The Third Affiliated Hospital of Guangxi Medical University, Nanning, Guangxi 530031, P.R. China

Received December 14, 2014; Accepted October 14, 2015

DOI: $10.3892 / 01.2015 .3913$

\begin{abstract}
Platinum-based chemotherapy is the first-line treatment for non-small cell lung cancer (NSCLC), but the chemotherapy often results in the development of chemoresistance. The present study aimed to explore the prognostic implications of survivin and lung resistance protein (LRP) in advanced NSCLC treated with platinum-based chemotherapy. Tumor samples were collected from 61 hospitalized patients with stage IIIB-IV NSCLC that underwent platinum-based chemotherapy. All patient samples were collected in the Oncology Department of the Third Affiliated Hospital of Guangxi Medical University between January 2006 and January 2011. Cytoplasmic survivin and LRP expression were evaluated using immunohistochemistry. The expression of LRP and survivin reached $77 \%$ (47/61) and $76 \%$ (45/61), respectively. Positive expression of survivin was associated with a lower median progression-free survival (PFS) time (4 vs. 9 months; $\mathrm{P}=0.038$ ) and a lower median overall survival (OS) time compared with the absence of survivin expression ( 9 vs. 16 months; $\mathrm{P}=0.039$ ). Patients with LRP and survivin expression $(n=41)$ demonstrated a median PFS time of 4 months. However, patients with either LRP or survivin expression $(n=10)$ demonstrated a median PFS time of 8 months, which is similar to the median PFS time of the 10 patients with no expression of LRP and survivin (9 months; $\mathrm{P}=0.022$ ). Either the expression of survivin or the combined expression of LRP and survivin is associated with a poor prognosis in advanced NSCLC treated with platinum-based chemotherapy.
\end{abstract}

Correspondence to: Professor Changjie Huang, Tumor Department, The Third Affiliated Hospital of Guangxi Medical University, 13 Dancun Road, Nanning, Guangxi 530031, P.R. China E-mail: changjie_huang@126.com

*Contributed equally

Key words: non-small cell lung cancer, lung resistance protein, survivin, platinum, drug resistance, prognosis

\section{Introduction}

Non-small cell lung cancer (NSCLC) accounts for $~ 85 \%$ of all lung cancers and is the leading cause of cancer-associated mortality worldwide (1). Platinum-based cytotoxic chemotherapy has been the first-line treatment for NSCLC for decades (2,3). Despite a consistent rate of initial response, platinum-based treatment often results in the development of chemoresistance, which leads to therapeutic failure (4). Although efforts to overcome resistance to targeted agents are ongoing, and utilize combination regimens of chemotherapy and targeted agents, the optimization of combination strategies requires additional exploration (5).

Survivin is a unique mammalian inhibitor of apoptosis proteins (6) and is selectively expressed in the majority of human cancers, among which the highest levels are found in lung and breast cancers (7). Survivin is considered a potential therapeutic target in multiple cancer types (8). The expression of survivin in patients with NSCLC is associated with a poor prognosis, as demonstrated in previous meta-analyses $(9,10)$. However, limited clinical data suggest that chemotherapy resistance in NSCLC is associated with survivin expression. The lung resistance protein (LRP) is a marker of chemoresistance in vitro and in vivo $(11,12)$. The over-expression of LRP predicts a poor response to chemotherapy in acute myeloid leukemia, ovarian carcinoma and multiple myeloma (13-15). LRP is differentially expressed in NSCLC cell lines and LRP expression is correlated with resistance to cisplatin (16). However, the prognostic value of LRP expression for the survival of patients with NSCLC remains controversial. In a study of 126 patients with NSCLC performed by Berger et al, the association between high LRP levels and long-term overall survival (OS) time was not statistically significant (17). However, in another study of 92 patients with NSCLC, a significant association was observed between LRP expression and a decrease in OS rate (18). Overall, in these two studies, only a small portion of the patients possessed advanced NSCLC, and not all of the included patients had received platinum-based chemotherapy. To explore the prognostic role of LRP and survivin in patients with advanced NSCLC that were treated with chemotherapy, the present study included patients with inoperable stage IIIB or IV NSCLC that were treated with only platinum-based 
chemotherapy. The present study examined the association between LRP and survivin expression, and investigated the prognostic role of LRP and survivin expression in patients with advanced NSCLC that were treated with platinum-based chemotherapy.

\section{Patients and methods}

Patients. The present study was approved by the Ethical Review Committee of The Third Affiliated Hospital of Guangxi Medical University (Nanning, Guangxi, China). All patients provided written informed consent to participate in the present study. This was a retrospective study. The specimens were obtained from 61 NSCLC patients with stage IIIB to IV disease, between January 2006 and January 2011. All stages were determined according to the 2013 National Comprehensive Cancer Network lung cancer tumor-node-metastasis (TNM) staging (19). The specimens were obtained through fiber bronchoscope biopsy, computed tomography or with ultrasonic-guided percutaneous transthoracic biopsy. The histological classification of NSCLC includes squamous cell carcinoma, adenocarcinoma and adenosquamous carcinoma, according to the World Health Organization criteria (20). Not all patients exhibited surgical indications, and certain patients refused to receive the surgical treatment and radiation therapy. No patients had multiple primary malignant tumors, and none had previously received anti-cancer therapy.

All patients received 2-6 cycles of platinum-based combination chemotherapy. The regimens consisted of cisplatin at a dose of $75 \mathrm{mg} / \mathrm{m}^{2}$ or carboplatin combined with gemcitabine at a dose of $1,000 \mathrm{mg} / \mathrm{m}^{2}$ on days 1 and 8 , or $25 \mathrm{mg} / \mathrm{m}^{2}$ vinorelbine on days 1 and 8 , or $175 \mathrm{mg} / \mathrm{m}^{2}$ paclitaxel on day 1 . The platinum-based doublet chemotherapy treatment was repeated every 3 weeks for a maximum of 6 cycles. If the patients presented three grades of non-hematology toxicity and four grades of hematology toxicity, the dose of chemotherapy agents was reduced by $25 \%$. The disease progression was assessed using chest X-rays and computed tomography scans. If the patient showed progressive disease or unacceptable toxicity, the chemotherapy treatment was stopped. All patients were followed-up by phone or outpatient appointments until January 2013 or until mortality. The follow-up time ranged between 2 and 29 months, and the median follow-up time was 7 months.

Immunohistochemistry (IHC). Paraformaldehyde-fixed and paraffin-embedded tissue sections $(4 \mu \mathrm{m})$ were stained according to the Envision method (21) using Envision IHC kits (Fuzhou New Biotechnology Development Co. Ltd, Fuzhou, Fujian, China). Briefly, the tissue sections were deparaffinized in xylene and rehydrated in graded alcohol solutions. Then, the sections were submerged in citrate buffer $(\mathrm{pH} \mathrm{6.0)}$ and autoclaved for $5 \mathrm{~min}$ for antigen retrieval. When the buffer cooled to room temperature, the sections were removed and washed twice in running water. Phosphate-buffered saline (PBS) was then used to wash the sections 3 times, with each wash lasting $3 \mathrm{~min}$. Next, endogenous peroxidase was blocked by incubation of the sections in $0.3 \%$ hydrogen peroxide for $10 \mathrm{~min}$ at room temperature. Subsequent to washing in PBS 3 times for 3 min, the samples were incubated with a rabbit anti-human polyclonal survivin antibody (cat. no. RAB0536; Fuzhou Maixin Biotechnology Development Co., Ltd. Fuzhou, China) and with a mouse anti-human monoclonal LRP antibody (cat. no. MAB0319; Fuzhou Maixin Biotechnology Development Co., Ltd.) diluted at 1:100 in PBS containing $0.5 \%$ bovine serum albumin overnight at $4^{\circ} \mathrm{C}$ in a humidified chamber. The sections were washed with PBS an additional 3 times for 3 min to remove unbound antibodies. Subsequent to removing the PBS, the sections were incubated with the Maxvision ${ }^{\mathrm{TM}}$ mouse/rabbit-horseradish peroxidase broad-spectrum detection kit (Asia Bioscience Co., Ltd., Taipei, Taiwan) for $15 \mathrm{~min}$ at room temperature. The sections were then washed with PBS 3 times for $3 \mathrm{~min}$. A $1 \mathrm{ml} \mathrm{3,3'-diaminobenzidine} \mathrm{(DAB)} \mathrm{color}$ reagent solution was prepared by mixing distilled water with DAB reagent. A total of $50 \mu 1 \mathrm{DAB}$ color reagent was added to each section for coloration. The sections were then washed in running water and counterstained with hematoxylin for $30 \mathrm{sec}$. The slides were washed in running deionized water and then dipped in lithium carbonate (Asia Bioscience Co., Ltd.). Subsequent to rinsing the slides in deionized water and counterstaining the slides with commercial hematoxylin, the slides were dehydrated and mounted. Appropriate tissue sections (thickness, $4 \mu \mathrm{m}$ ) were used as positive controls for each primary antibody and were stained simultaneously. PBS was used as the negative control at the same dilutions as the corresponding primary antibodies. The Olympus BX51 microscopic/Digital Camera System (Olympus, Tokyo, Japan) was used to capture images of the sections.

Evaluation of the immunohistochemical staining. Evaluation of the staining for the expression of survivin and LRP was conducted with bright-field light microscopy independently by two experienced pathologists, who did not have knowledge of the results of the ligand-binding assay or the patient outcome. Stained tissue sections were examined at a magnification of x100 under a light microscope (BX60; Olympus). LRP and survivin staining was noted to be yellow or brown-orange, with a granulated, pieced or zonal arrangement and without any background staining. Five fields per slide were selected, the number of immunopositive cells was counted from each section and the mean was calculated. Survivin and LRP expression in the cytoplasm was classified semi-quantitatively by combining the proportion and intensity of the positively stained tumor cells. The percentage of positively stained tumor cells was scored as follows: 0 , no stained tumor cells; $1,10 \%$ of tumor cells were stained; $2,11-50 \%$ of tumor cells were stained; $3,51-75 \%$ of tumor cells were stained; and $4,>75 \%$ of tumor cells were stained. The staining intensity was scored as follows: 0 , no staining; 1 , mild yellow; 2 , brown-orange; and 3, brown (22). The product of the staining intensity score and the percentage of positive staining were used to define the expression levels. A final score of $0-3$ was considered to indicate no protein expression, whereas a score of $>3$ was considered to indicate protein expression. Furthermore, according to the scores, the lung cancer patients were classified into three groups, consisting of the negative expression group (score, 0 ), the low expression group (score, 2-4) and the high expression group (score, 5).

Evaluation of the therapeutic efficacy. The objective therapeutic efficacy was assessed using chest X-rays and 

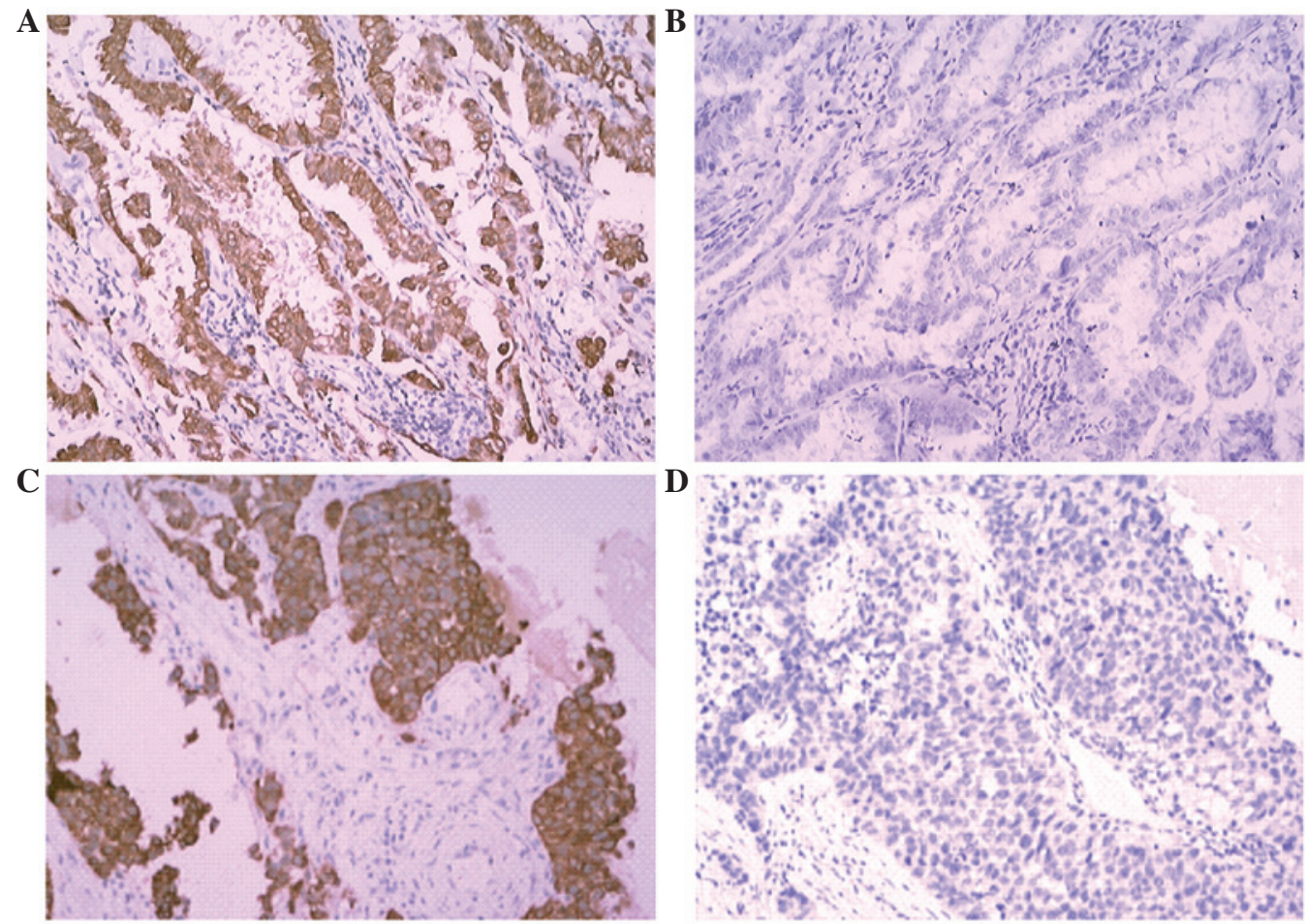

Figure 1. Representative images of the expression of survivin and LRP in advanced NSCLC tissues (scanning probe microscope; magnification, x100). (A) Expression of survivin. (B) No expression of survivin. (C) Expression of LRP. (D) No expression of LRP. LRP, lung resistance protein.

computed tomography scans, according to the Response Evaluation Criteria in Solid Tumors (version 1.1) criteria (23), which contained the following parameters: CR, complete response; PR, partial remission; PD, progressive disease; and $\mathrm{SD}$, stable disease. In CR the tumor disappears entirely for $\geq 4$ weeks. In PR the maximum diameter of the tumor is reduced by $\geq 30 \%$, and this reduction is maintained for $\geq 4$ weeks. In PD the maximum diameter of the tumor has increased $\geq 20 \%$ or novel lesions have developed, and in $\mathrm{SD}$, tumor shrinkage is not sufficient to qualify for PR and tumor increase is not sufficient to qualify for PD. CR and PR were considered effective responses, and SD and PD were considered ineffective responses. The objective response probability was calculated according to the effective responses. Progression-free survival (PFS) was calculated from the chemotherapy start date to PD, which was assessed using chest X-rays and computed tomography scans. OS was calculated from the chemotherapy start date to the date of mortality or last clinical follow-up.

Statistical analysis. Statistical analyses were performed using the Statistical Package for the Social Sciences version 16.0 (SPSS, Inc., Chicago, IL, USA). Pearson's $\chi^{2}$ test or Fisher's exact test was used to compare the clinicopathological parameters, including patient gender, histological type, degree of differentiation, primary focal range, lymph node metastasis and staging of the disease, with the presence on absence of survivin or LRP expression. The cumulative survival rates were calculated using Kaplan-Meier survival analysis and were compared using the log-rank test. A value of $\mathrm{P}<0.05$ was considered to indicate a statistically significant result. All reported $\mathrm{P}$-values are two-sided.

\section{Results}

The present study assessed 61 patients with advanced NSCLC. Experimental data and follow-up data were obtained for all patients. The expression of survivin and LRP is exhibited in Fig. 1. There were 46 male and 15 female patients, with a median age of 56 years (range, 32-74 years). Out of these patients, 34 were current or former smokers $(55.7 \%)$, and 27 were never smokers $(44.3 \%)$. Squamous cell carcinoma was the most prevalent histological diagnosis (33 patients; $54.1 \%$ ), followed by adenocarcinoma (20 patients; $32.8 \%$ ), and adenosquamous carcinoma (8 patients; 13.1\%). According to the TNM staging criteria, 22 patients had stage IIIB NSCLC, and 39 patients had stage IV NSCLC.

The association between the clinical features and the expression of survivin or LRP is reported in Table I. The distribution of $\mathrm{T}$ stages in the survivin-positive group and in the survivin-negative group was significantly different $(\mathrm{P}<0.001)$. In the survivin-positive group, more patients had stage IV lung cancer than stage IIIB lung cancer, but the difference was not statistically significant $(\mathrm{P}=0.361)$. The patients with LRP expression were more likely to be in stage M1 than in stage M0 ( $\mathrm{P}=0.042)$, and therefore were more likely to have stage IV lung cancer than stage IIIB lung cancer $(\mathrm{P}=0.042)$. No significant differences were observed in the incidence of survivin or LRP expression with respect to patient age, patient gender, smoking, $\mathrm{N}$ stage, differentiation levels and histological types.

The rate of survivin expression was $73.8 \%$ (45 out of 61 patients), and the rate of LRP-positive expression was $77.0 \%$ (47 out of 61 patients). The rates of survivin and LRP expression in advanced NSCLC tissues are reported in Table II. The rate of LRP expression in the survivin-positive group was 
Table I. Association between LRP or survivin expression and clinical characteristics in non-small cell lung cancer.

\begin{tabular}{|c|c|c|c|c|c|c|}
\hline & \multicolumn{2}{|c|}{ Survivin expression, n (\%) } & \multirow[b]{2}{*}{ P-value } & \multicolumn{2}{|c|}{ LRP expression, n (\%) } & \multirow[b]{2}{*}{ P-value } \\
\hline & - & + & & - & + & \\
\hline Age, years & $55.9 \pm 12.3$ & $53.9 \pm 10.9$ & 0.557 & $57.8 \pm 11.5$ & $53.4 \pm 11.1$ & 0.207 \\
\hline \multicolumn{7}{|l|}{ Gender } \\
\hline Male & $13(81.25)$ & $33(73.30)$ & \multirow[t]{2}{*}{0.528} & $13(92.86)$ & $33(70.21)$ & \\
\hline Female & $3(18.75)$ & $12(26.67)$ & & $1(7.14)$ & $14(29.79)$ & \\
\hline \multicolumn{7}{|l|}{ Smoking status } \\
\hline Current or former smokers & $7(43.75)$ & $27(60.00)$ & \multirow[t]{2}{*}{0.261} & $6(42.86)$ & $28(59.57)$ & \multirow[t]{2}{*}{0.269} \\
\hline Non-smokers & $9(56.25)$ & $18(40.00)$ & & $8(57.14)$ & $19(40.43)$ & \\
\hline \multicolumn{7}{|l|}{ Histology } \\
\hline Squamous cell carcinoma & $8(50.00)$ & $25(55.56)$ & \multirow[t]{3}{*}{0.896} & $10(71.43)$ & $23(48.94)$ & \multirow[t]{3}{*}{0.330} \\
\hline Adenocarcinoma & $6(37.50)$ & $14(31.11)$ & & $3(7.14)$ & $17(36.17)$ & \\
\hline Adenosquamous carcinoma & $2(12.50)$ & $6(13.33)$ & & $1(100.00)$ & $7(14.89)$ & \\
\hline \multicolumn{7}{|l|}{ Differentiation } \\
\hline Low level & $16(100.00)$ & $37(82.22)$ & \multirow[t]{3}{*}{0.195} & $14(100.00)$ & $39(82.98)$ & \multirow[t]{3}{*}{0.254} \\
\hline Medium level & $0(0.00)$ & $7(15.56)$ & & $0(0.00)$ & $7(14.89)$ & \\
\hline High level & $0(0.00)$ & $1(2.22)$ & & $0(0.00)$ & $1(2.13)$ & \\
\hline \multicolumn{7}{|l|}{ TNM stage } \\
\hline IIIB & $7(43.75)$ & $14(31.11)$ & \multirow[t]{2}{*}{0.361} & $8(57.14)$ & $13(27.66)$ & \multirow[t]{2}{*}{0.042} \\
\hline IV & $9(56.25)$ & $31(68.89)$ & & $6(42.86)$ & $34(72.34)$ & \\
\hline \multicolumn{7}{|l|}{ T stage } \\
\hline $\mathrm{T} 1$ & $2(12.50)$ & $1(2.22)$ & \multirow[t]{4}{*}{0.001} & $1(7.14)$ & $2(4.26)$ & \multirow[t]{4}{*}{0.149} \\
\hline $\mathrm{T} 2$ & $3(18.75)$ & $20(41.44)$ & & $2(14.29)$ & $21(44.68)$ & \\
\hline $\mathrm{T} 3$ & $2(12.50)$ & $18(40.00)$ & & $5(35.71)$ & $15(31.91)$ & \\
\hline $\mathrm{T} 4$ & $9(56.25)$ & $6(13.33)$ & & $6(42.86)$ & $9(19.15)$ & \\
\hline \multicolumn{7}{|l|}{$\mathrm{N}$ stage } \\
\hline No & $0(0.00)$ & $3(6.67)$ & \multirow[t]{4}{*}{0.638} & $1(7.14)$ & $2(4.26)$ & \multirow[t]{4}{*}{0.952} \\
\hline $\mathrm{N} 1$ & $3(18.75)$ & $5(11.11)$ & & $2(14.29)$ & $6(12.77)$ & \\
\hline $\mathrm{N} 2$ & $6(37.50)$ & $19(42.22)$ & & $5(35.71)$ & $20(42.55)$ & \\
\hline N3 & $7(43.75)$ & $18(40.00)$ & & $6(42.86)$ & $19(40.43)$ & \\
\hline \multicolumn{7}{|l|}{ M stage } \\
\hline M0 & $7(43.75)$ & $14(31.11)$ & \multirow[t]{2}{*}{0.361} & $8(57.14)$ & $13(27.66)$ & \multirow[t]{2}{*}{0.042} \\
\hline M1 & $9(56.25)$ & $31(68.89)$ & & $6(42.86)$ & $34(72.34)$ & \\
\hline
\end{tabular}

TNM, tumor-node-metastasis; LRP, lung resistance protein.

significantly higher compared with the rate of LRP expression in the survivin-negative group (91.11 vs. $37.50 \%$, respectively; $\mathrm{P}<0.001)$. The rate of survivin and LRP expression was $67.2 \%$, and the rate of the absence of the two proteins was only $6.1 \%$.

Following platinum-based chemotherapy, 0 patients demonstrated CR, 27 patients demonstrated PR, 13 patients demonstrated SD, and 21 patients demonstrated PD. The rate of effective or objective response to chemotherapy reached $55.7 \%$. The objective response probability (OR), PFS and OS data, according to the expression of survivin or LRP, are summarized in Fig. 2. As revealed in Fig. 2A and B, the presence of survivin expression was associated with a decreased median PFS time compared with the absence of expression (4.0 vs. 9.0 months, respectively; log-rank test, $\mathrm{P}=0.038$ ), and was also associated with a decreased median OS time compared with the absence of expression (9.0 vs. 16.0 months, respectively; log-rank test, $\mathrm{P}=0.039$ ). As revealed in Fig. $2 \mathrm{C}$, the patients without LRP expression demonstrated a $71.4 \%$ probability of response (10 out of 14 patients), which was significantly greater than the probability of response for patients with LRP expression (40.0\%; 19 out of 47 patients) $(\mathrm{P}=0.041)$. In addition, the expression of LRP was associated with a decreased median OS time compared with the absence of expression (9.0 vs. 16.0 months, respectively; log-rank test, $\mathrm{P}=0.043)$, although no significant difference was observed between the median PFS times (5.0 vs. 9.0 months, respectively; log-rank test, $\mathrm{P}=0.106$ ).

The outcome of all patients was subsequently analyzed according to the expression of LRP and survivin (Fig. 3). Patients with LRP and survivin expression $(n=41)$ demonstrated 
Table II. Association between LRP and survivin expression in non-small cell lung cancer.

\begin{tabular}{lrcr}
\hline & Survivin (-) & Survivin (+) & P-value \\
\hline LRP (-) & $10(62.50)$ & $4(8.89)$ & $<0.001$ \\
LRP (+) & $6(37.50)$ & $41(91.11)$ & \\
\hline
\end{tabular}

P-value was calculated using the $\chi^{2}$ test. LRP, lung resistance protein; NSCLC, non-small cell lung cancer.

a median PFS time of 4 months [95\% confidence interval (CI), 2.7-5.3], whereas patients with the expression of either LRP or survivin $(\mathrm{n}=10)$ demonstrated a median PFS time of 8 months (95\% CI, 4.0-12.0), which was similar to the median PFS time of the 10 patients with no LRP or survivin expression (9 months; 95\% CI, 2.9-15.1; P=0.022) (Fig. 3A). However, the difference in median OS time between the patients with tumors that expressed survivin and LRP, and the OS time of patients with tumors that expressed either survivin or LRP or neither protein, was not statistically significant $(\mathrm{P}=0.059$; Fig. 3B).

\section{Discussion}

The mechanism of clinical drug resistance in NSCLC is multi-factorial. The expression of survivin or LRP in the tumor is one of the factors that may limit the efficacy of chemotherapy in NSCLC. The results of the present study indicate that either the expression of survivin alone or the expression of survivin and LRP may be associated with a poor prognosis in patients with advanced NSCLC that are treated with platinum-based chemotherapy. With respect to survivin as a potential therapeutic target in NSCLC, the present findings may support the requirement for additional studies that integrate chemotherapy and targeted therapeutics as a novel strategy.

The prognostic implication of survivin in NSCLC has been previously studied. A meta-analysis has shown that the expression of the survivin protein was a poor prognostic factor for the survival of patients with NSCLC. However, this association was only found in patients with stage III-IV NSCLC, which is consistent with the present study, and was not identified in patients with stage I-II NSCLC (9). Since the expression of survivin is more likely to be associated with a poor prognosis in patients with advanced NSCLC, only the patients with inoperable tumors with stages IIIB and IV NSCLC were included in the present study. In addition, the majority of previous studies lack details on patient treatment $(9,10)$. As various therapies and, in particular, targeted therapies may affect the survival of patients with NSCLC, only the patients that received platinum-based chemotherapy were included in the present study. This is similar to a previous study in which the patients received a chemotherapy regimen that consisted of cisplatin and etoposide ( 2 cycles) prior to surgery (24). However, the patients in the previous study had stage IIB and IIIA NSCLC, which differed from the patients with advanced NSCLC in the present study. Additionally, the survivin expression in this study was assessed by in situ hybridization (ISH). Compared with ISH or polymerase chain reaction (PCR), the IHC applied in the present study was more simple and cost-effective in clinical use (9). Since the role of nuclear survivin in the OS rate of patients with NSCLC has remained controversial, survivin expression has been detected and considered in the cytoplasm, but not in the nucleus $(9,10)$. Overall, the present study enrolled patients with inoperable stages IIIB and IV NSCLC that were treated only with platinum-based chemotherapy. The design of the present study allowed the characterization of the association between survivin expression in the cytoplasm and the prognosis of patients with advanced NSCLC that were treated by platinum-based chemotherapy.

The prognostic implication of LRP expression in NSCLC has been previously studied. LRP is a member of the membrane transporter protein family and was originally identified in a multidrug-resistant lung cancer cell line (25). Classical multi-drug resistance is mediated by drug efflux mechanisms. Multidrug resistance protein (MRP) and LRP are involved in drug resistance in NSCLC cell lines $(16,26,27)$. The positive expression of MRP and LRP has been associated with decreased survival in patients with NSCLC (18). The rate of LRP-positive expression in the previous study reached $52 \%$ (40/92) (18), but the rate in the present study reached $77 \%$ (47/61). The high rate of LRP-positive expression in the present study may be due to the larger number of cases of advanced NSCLC in the present study. It has been previously reported that the expression of LRP is associated with chemotherapy resistance in acute myelocytic leukemia, ovarian carcinoma and multiple myeloma (13-15). In NSCLC cell lines, LRP is differentially expressed and correlates with resistance to cisplatin (16). LRP expression has been demonstrated to be inversely correlated with the response to chemotherapy in advanced NSCLC, which is consistent with the present findings (28). In the present study, the presence of LRP expression was associated with a decreased median OS and PFS time compared with the absence of LRP expression, although the difference in PFS time was not statistically significant. However, another previous study failed to detect any association between the expression of LRP and the response to chemotherapy in patients with advanced NSCLC (29). Overall, the prognostic role of LRP in NSCLC has not been confirmed.

The combination of two or more biomarkers for the prediction of drug resistance in NSCLC is not a novel design (30-32). The assessment of survivin expression has been combined with the assessment of other markers and has provided valuable information in the prognosis of NSCLC. For example, the combination of p53AIP1 and survivin gene expression has been demonstrated as a powerful tool to stratify subgroups with better or worse prognoses from the variable NSCLC population (33). In another study, the combination of survivin expression and the levels of HMGB1 and VEGF had no clinical significance in the prognosis of the survival time in patients with lung cancer (34). In the present study, although there was no statistical significance in the OS time between patients expressing survivin and LRP and patients expressing neither or only one protein, the median OS time in patients with tumors that expressed survivin or LRP was significantly lower compared with the median OS time in patients without LRP expression. To best of our knowledge, the present study is the first to assess combined survivin and LRP expression to study the prognostic implications of these proteins in patients 
A

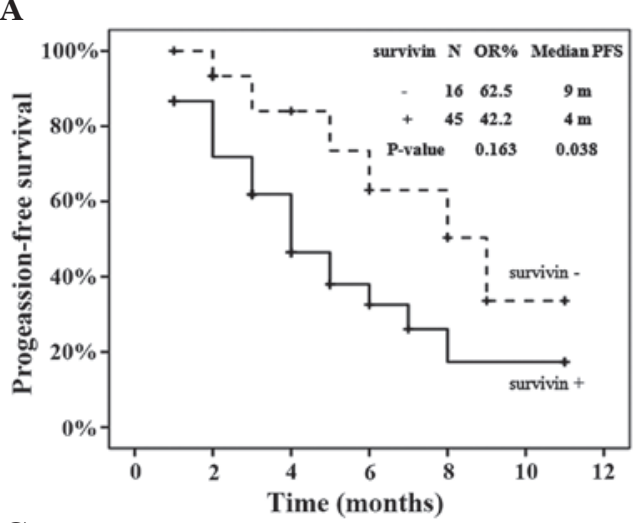

C

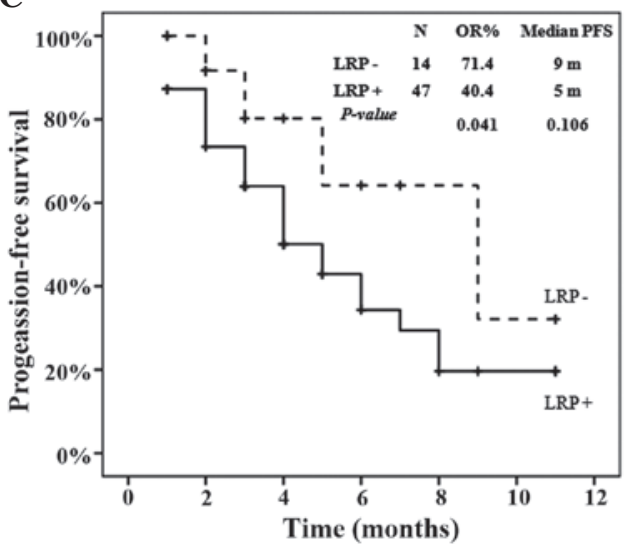

B

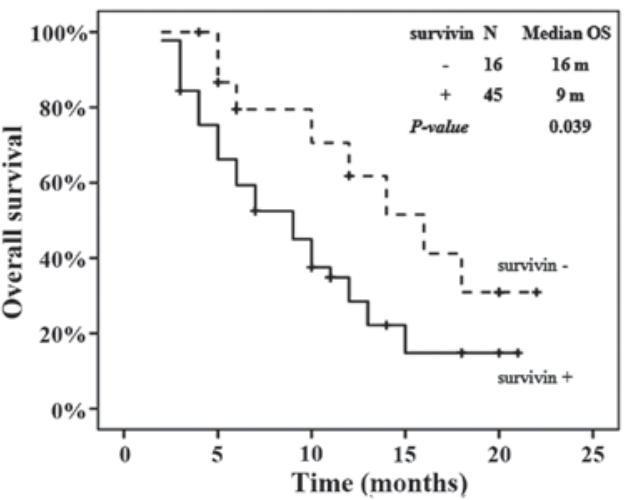

D

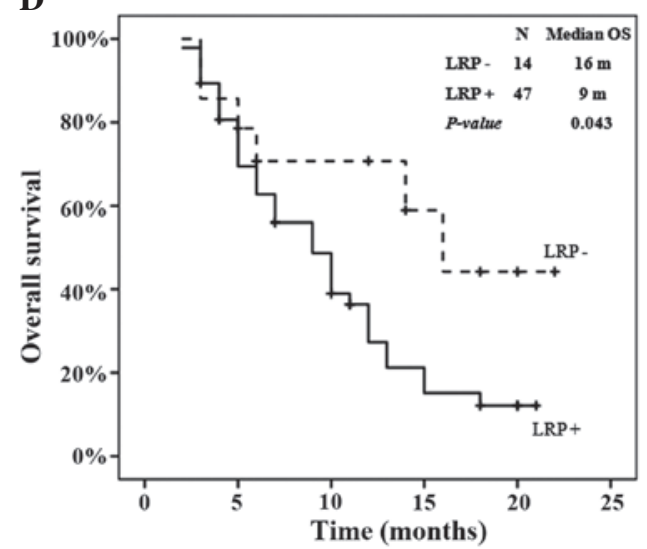

Figure 2. OR, PFS and OS according to survivin or LRP expression. (A) PFS in terms of survivin expression; (B) OS in terms of survivin expression; (C) PFS in terms of LRP expression; (D) OS in terms of LRP expression. OR, objective response; PFS, progression-free survival; OS, overall survival; LRP, lung resistance protein.
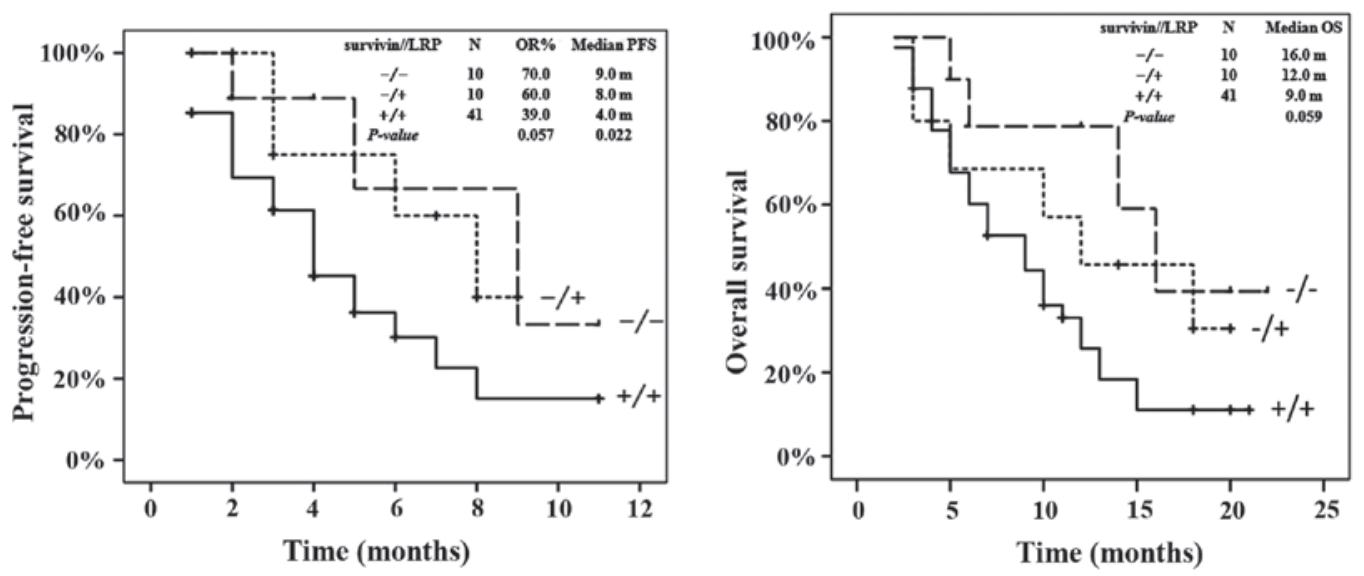

Figure 3. OR, PFS and OS according to survivin or LRP expression. The log-rank P-value indicates the comparison of patients with expression of survivin and LRP vs. expression of one protein or no expression of LRP or survivin. OR, objective response; PFS, progression-free survival; OS, overall survival; LRP, lung resistance protein.

with advanced NSCLC treated with platinum-based chemotherapy.

Although the strength of the present study was characterized by the measurement of LRP and survivin levels in patients with advanced NSCLC that were treated with platinum-based chemotherapy, three important limitations must be recognized. First, the size of the studied population was relatively small, and the $95 \%$ CIs were large and overlapping; therefore, the conclusion of the statistical significance between the groups should be made with caution. Second, the IHC used to detect the expression of survivin and LRP in the present study was not a quantitative approach, although it could be easily generalized in clinical use due to the simplicity and low cost of the ISH. The current findings may be confirmed by measuring the mRNA and protein levels of survivin and LRP, or generating a patient-derived xenograft of NSCLC. Finally, the present study detected the expression of survivin in the cytoplasm, but not in the nucleus, as the nuclear expression of survivin may be a prognostic factor 
in patients with resected stage I-IIIA NSCLC, but not in patients with inoperable stages IIIB and IV NSCLC (35).

High expression of survivin may inhibit the apoptosis induced by anticancer drugs. Chemotherapy resistance in NSCLC may be associated with high expression of survivin due to the ability of survivin to inhibit the apoptosis induced by anticancer drugs (36). LRP, as a membrane transporter protein, may be associated with drug resistance by drug efflux mechanisms (25). The present results showed that the combination of survivin and LRP expression is associated with a poor prognosis in patients with advanced NSCLC that were treated with platinum-based chemotherapy, which indicates that LRP may function in the apoptosis pathway characterized by survivin (37).

In conclusion, the present study found that the expression of survivin or combined expression of LRP and survivin is associated with a poor prognosis in patients with advanced NSCLC that are treated with platinum-based chemotherapy.

\section{Acknowledgements}

This study was supported by the Guangxi Natural Science Foundation (grant no. 2010GXNSFA013260) and the Nanning City Science and Technology Development Program (grant no. 201003045C-6).

\section{References}

1. Jemal A, Siegel R, Ward E, Hao Y, Xu J and Thun MJ: Cancer statistics, 2009. CA Cancer J Clin 59: 225-249, 2009.

2. Zarogoulidis K, Zarogoulidis P, Darwiche K, Boutsikou E, Machairiotis N, Tsakiridis K, Katsikogiannis N, Kougioumtzi I, Karapantzos I, Huang H and Spyratos D: Treatment of non-small cell lung cancer (NSCLC). J Thorac Dis 5 (Suppl 4): S389-S396, 2013.

3. Rosell R, Gómez-Codina J, Camps C, Maestre J, Padille J, Cantó A, Mate JL, Li S, Roig J, Olazábal A, et al: A randomized trial comparing preoperative chemotherapy plus surgery with surgery alone in patients with non-small-cell lung cancer. N Engl J Med 330: 153-158, 1994.

4. Polo V and Besse B: Maintenance strategies in stage IV non-small-cell lung cancer (NSCLC): In which patients, with which drugs? Ann Oncol 25: 1283-1293, 2014.

5. Lwin Z, Riess JW and Gandara D: The continuing role of chemotherapy for advanced non-small cell lung cancer in the targeted therapy era. J Thorac Dis 5 (Suppl 5): S556-S564, 2013.

6. Escuín D and Rosell R: The anti-apoptosis survivin gene and its role in human cancer: An overview. Clin Lung Cancer 1: 138-143, 1999.

7. Ambrosini G, Adida C and Altieri DC: A novel anti-apoptosis gene, survivin, expressed in cancer and lymphoma. Nat Med 3: 917-921, 1997.

8. Cheung CH, Huang CC, Tsai FY, Lee JY, Cheng SM, Chang YC, Huang YC, Chen SH and Chang JY: Survivin - biology and potential as a therapeutic target in oncology. Onco Targets Ther 6: 1453-1462, 2013.

9. Zhang LQ, Wang J, Jiang F, Xu L, Liu FY and Yin R: Prognostic value of survivin in patients with non-small cell lung carcinoma: A systematic review with meta-analysis. PloS One 7: e34100, 2012 .

10. Huang LN, Wang DS, Chen YQ, Zhao CL, Gong BL, Jiang AB, Jia W and Hu FD: Expression of survivin and patients survival in non-small cell lung cancer: A meta-analysis of the published studies. Mol Biol Rep 40: 917-924, 2013.

11. Scheffer GL, Wijngaard PL, Flens MJ, Izquierdo MA, Slovak ML, Pinedo HM, Meijer CJ, Clevers HC and Scheper RJ: The drug resistance-related protein LRP is the human major vault protein. Nat Med 1: 578-582, 1995.

12. Kickhoefer VA, Rajavel KS, Scheffer GL, Dalton WS, Scheper RJ and Rome LH: Vaults are up-regulated in multidrug-resistant cancer cell lines. J Biol Chem 273: 8971-8974, 1998.
13. Izquierdo MA, van der Zee AG, Vermorken JB, van der Valk $P$, Beliën JA, Giaccone G, Scheffer GL, Flens MJ, Pinedo HM, Kenemans P, et al: Drug resistance-associated marker Lrp for prediction of response to chemotherapy and prognoses in advanced ovarian carcinoma. J Natl Cancer Inst 87: 1230-1237, 1995.

14. Hart SM, Ganeshaguru K, Scheper RJ, Prentice HG, Hoffbrand AV and Mehta AB: Expression of the human major vault protein LRP in acute myeloid leukemia. Exp Hematol 25: 1227-1232, 1997.

15. Raaijmakers HG, Izquierdo MA, Lokhorst HM, de Leeuw C, Belien JA, Bloem AC, Dekker AW, Scheper RJ and Sonneveld P: Lung-resistance-related protein expression is a negative predictive factor for response to conventional low but not to intensified dose alkylating chemotherapy in multiple myeloma. Blood 91: 1029-1036, 1998.

16. Berger W, Elbling L and Micksche M: Expression of the major vault protein LRP in human non-small-cell lung cancer cells: Activation by short-term exposure to antineoplastic drugs. Int J Cancer 88: 293-300, 2000.

17. Berger W, Setinek U, Hollaus P, Zidek T, Steiner E, Elbling L, Cantonati H, Attems J, Gsur A and Micksche M: Multidrug resistance markers P-glycoprotein, multidrug resistance protein 1 , and lung resistance protein in non-small cell lung cancer: Prognostic implications. J Cancer Res Clin Oncol 131: 355-363, 2005.

18. Chen ZJ, Le HB, Zhang YK, Qian LY, Sekhar KR and Li WD: Lung resistance protein and multidrug resistance protein in non-small cell lung cancer and their clinical significance. J Int Med Res 39: 1693-1700, 2011.

19. Kalemkerian GP, Akerley W, Bogner P, Borghaei H, Chow LQ, Downey RJ, Gandhi L, Ganti AK, Govindan R, Grecula JC, et al; National Comprehensive Cancer Network: Small cell lung cancer. J Natl Compr Canc Netw 11: 78-98, 2013.

20. Brambilla E, Travis WD, Colby TV, Corrin B and Shimosato Y: The new World Health Organization classification of lung tumours. Eur Respir J 18: 1059-1068, 2001.

21. Dingemans AM, van Ark-Otte J, van der Valk P, Apolinario RM, Scheper RJ, Postmus PE and Giaccone G: Expression of the human major vault protein LRP in human lung cancer samples and normal lung tissues. Ann Oncol 7: 625-630, 1996.

22. Klunder JW, Komdeur R, van der Graaf WT, et al: Expression of multidrug resistance-associated proteins in rhabdomyosarcomas before and after chemotherapy: The relationship between lung resistance-related protein (LRP) and differentiation. Hum Pathol 34: 150-155, 2003.

23. Eisenhauer EA, Therasse P, Bogaerts J, Schwartz LH, Sargent D, Ford R, Dancey J, Arbuck S, Gwyther S, Mooney M, et al: New response evaluation criteria in solid tumours: Revised RECIST guideline (version 1.1). Eur J Cancer 45: 228-247, 2009.

24. Karczmarek-Borowska B, Filip A, Wojcierowski J, Smoleń A, Pilecka I and Jabłonka A: Survivin antiapoptotic gene expression as a prognostic factor in non-small cell lung cancer: In situ hybridization study. Folia Histochem Cytobiol 43: 237-242, 2005.

25. Scheper RJ, Broxterman HJ, Scheffer GL, Kaaijk P, Dalton WS, van Heijningen TH, van Kalken CK, Slovak ML, de Vries EG, van der Valk P, et al: Overexpression of a M(r) 110,000 vesicular protein in non-P-glycoprotein-mediated multidrug resistance. Cancer Res 53: 1475-1479, 1993.

26. Young LC, Campling BG, Cole SP, Deeley RG and Gerlach JH: Multidrug resistance proteins MRP3, MRP1, and MRP2 in lung cancer: Correlation of protein levels with drug response and messenger RNA levels. Clin Cancer Res 7: 1798-1804, 2001.

27. Young LC, Campling BG, Voskoglou-Nomikos T, Cole SP, Deeley RG and Gerlach JH: Expression of multidrug resistance protein-related genes in lung cancer: Correlation with drug response. Clin Cancer Res 5: 673-680, 1999.

28. Harada T, Ogura S, Yamazaki K, Kinoshita I, Itoh T, Isobe H, Yamashiro K, Dosaka-Akita H and Nishimura M: Predictive value of expression of $\mathrm{P} 53, \mathrm{Bcl}-2$ and lung resistance-related protein for response to chemotherapy in non-small cell lung cancers. Cancer Sci 94: 394-399, 2003.

29. Dingemans AC, van Ark-Otte J, Span S, Scagliotti GV, van der Valk P, Postmus PE and Giaccone G: Topoisomerase IIalpha and other drug resistance markers in advanced non-small cell lung cancer. Lung Cancer 32: 117-128, 2001.

30. Wang TB, Zhang NL, Wang SH, Li HY, Chen SW and Zheng YG: Expression of ERCC1 and BRCA1 predict the clinical outcome of non-small cell lung cancer in patients receiving platinum-based chemotherapy. Genet Mol Res 13: 3704-3710, 2014. 
31. Xie KJ, He HE, Sun AJ, Liu XB, Sun LP and Dong XJ: Expression of ERCC1, MSH2 and PARP1 in non-small cell lung cancer and prognostic value in patients treated with platinum-based chemotherapy. Asian Pac J Cancer Prev 15: 2591-2596, 2014.

32. Kaira K, Yamamoto N, Kenmotsu H, Murakami H, Ono A, Naito T, Endo M and Takahashi T: Prognostic impact of 18F-FDG uptake on PET in non-small cell lung cancer patients with postoperative recurrence following platinum-based chemotherapy. Respir Investig 52: 121-128, 2014.

33. Yamashita S, Chujo M, Miyawaki M, Tokuishi K, Anami K, Yamamoto S and Kawahara K: Combination of p53AIP1 and survivin expression is a powerful prognostic marker in non-small cell lung cancer. J Exp Clin Cancer Res 28: 22, 2009.
34. Naumnik W, Nilklińska W, Ossolińska M and Chyczewska E: Serum levels of HMGB1, survivin, and VEGF in patients with advanced non-small cell lung cancer during chemotherapy. Folia Histochem Cytobiol 47: 703-709, 2009.

35. Hu S, Qu Y, Xu X, Xu Q, Geng J and Xu J: Nuclear survivin and its relationship to DNA damage repair genes in non-small cell lung cancer investigated using tissue array. PloS One 8: e74161, 2013.

36. Stewart DJ: Tumor and host factors that may limit efficacy of chemotherapy in non-small cell and small cell lung cancer. Crit Rev Oncol Hematol 75: 173-234, 2010.

37. Singhal S, Vachani A, Antin-Ozerkis D, Kaiser LR and Albelda SM: Prognostic implications of cell cycle, apoptosis, and angiogenesis biomarkers in non-small cell lung cancer: A review. Clin Cancer Res 11: 3974-3986, 2005. 